\title{
Influence of coating soil types on the energy of earth-air heat exchanger
}

\author{
Mathias Cuny ${ }^{\mathrm{a}, *}$, Jian Lin ${ }^{\mathrm{b}}$, Monica Siroux ${ }^{\mathrm{a}}$, Vincent Magnenet ${ }^{\mathrm{b}}$, Christophe Fond $^{\mathrm{a}}$ \\ a ICube UMR 7357, INSA de Strasbourg, 24 Bd de la Victoire, 67000 Strasbourg, France \\ ${ }^{\mathrm{b}}$ ICube UMR 7357, IUT Robert Schuman, 72 Route du Rhin, 67411 Illkirch-Graffenstaden, France
}

\section{A R T I C L E I N F O}

\section{Article history:}

Received 7 December 2016

Received in revised form 5 October 2017

Accepted 14 October 2017

Available online 16 October 2017

\section{Keywords:}

Renewable energy

Earth-air heat exchanger

Transient simulation

Finite elements

\begin{abstract}
A B S T R A C T
In this paper, a study is conducted to quantify the impact of coating soil types on the energetic performance of an earth-air heat exchanger (EAHE). A new numerical modelling based on the finite element method and taking thermal properties of soils as inputs is first proposed. Afterwards, the model is validated with experimental measurements of temperature in soil and in the EAHE, at the University of Strasbourg in France, which contains three different types of coating soils at different parts of the buried pipe. To evaluate the energy impact of the different types of coatings soils, numerical modellings are carried out for a typical EAHE configuration with these three coating soils along the entire length of the pipe. The obtained results show that both the moisture content and the soil type have non-negligible influence on the EAHE's thermal performance. In extreme cases, the difference of energy performance between a sand with a minimum humidity and a mix for a maximum humidity, measured in the experimental EAHE, reached $17.4 \%$ for the same period.
\end{abstract}

(c) 2017 Elsevier B.V. All rights reserved.

\begin{tabular}{|c|c|}
\hline \multicolumn{2}{|c|}{ Nomenclature } \\
\hline \multicolumn{2}{|c|}{ Letter Description Unit } \\
\hline$a$ & Thermal diffusivity $\mathrm{m}^{2} . \mathrm{s}^{-1}$ \\
\hline$\lambda$ & Thermal conductivity $\mathrm{W} \cdot \mathrm{m}^{-1} \cdot \mathrm{K}^{-1}$ \\
\hline$\rho$ & Density kg. $\mathrm{m}^{-3}$ \\
\hline$c_{p}$ & Specific heat capacity $\mathrm{J} \cdot \mathrm{kg}^{-1} \cdot \mathrm{K}^{-1}$ \\
\hline C & Volumetric heat capacity $\mathrm{J} \cdot \mathrm{m}^{-3} \cdot \mathrm{K}^{-1}$ \\
\hline$h$ & Convective heat exchange coefficient W. $\mathrm{m}^{-2} \cdot \mathrm{K}^{-1}$ \\
\hline$T$ & Temperature ${ }^{\circ} \mathrm{C}$ \\
\hline$z$ & Exchanger's depth m \\
\hline$L$ & Exchanger's length m \\
\hline$r$ & Pipe's radius m \\
\hline$H R$ & Relative humidity \% \\
\hline
\end{tabular}

\section{Introduction}

An earth-air heat exchanger (EAHE) usually consists of a simple pipe buried in the ground. Air circulates through the pipe and interacts with its wall at a temperature which is close to that of soil temperature. In winter, soil temperature warms the air tempera-

\footnotetext{
* Corresponding author.

E-mail address: mathias.cuny@insa-strasbourg.fr (C. Fond).
}

ture inside the pipe. In summer, the reverse phenomena happens and is referred to as cooling. Because of the cost of landfill work, the depth of an EAHE is, mostly, between 1 and $3 m$ in depth. EAHEs are primarily used in two sectors: buildings and agricultural greenhouses. Energy savings with this technology is proven, as shown in the article of Santamouris and Kolokotsa [1]. They list 30 pilot projects around the world under two different climatic conditions: low temperate and warm climate. The types of buildings connected to the previous EAHE represent a wide range of existing buildings (e.g. offices, shops, private housing and universities et cetera) with an area ranging from 30 to $16000 \mathrm{~m}^{2}$. The recent development of EAHEs clearly shows that theoretical studies must be carried out to understand and quantify the role of parameters controlling the evolution of an EAHE (e.g. pipe's radius, pipe's depth, and a soil's properties), with the main objective of optimizing efficiency.

Generally, the energy efficiency of an EAHE depends on the following:

The configuration of the exchanger: In Iran, Abbaspour-Fard et al. [2] tested the performance of an EAHE system on various parameters such as the buried depth and the pipe's length. After 72 experimental trials, it has been concluded that all parameters were directly related to energy performance;

- Climatic conditions: Li et al. [3] conceived an experimental setup, at Herbin in China, to study a ground sink direct cooling system in several cold areas. They concluded that there was substantial scope of energy conservation within a particular region showing 
that geographical and climatic conditions had a major impact on the energetic performance of their system. In the same context, Popiel et al. [4] present the temperature distributions measured with thermocouples, at a depth from 0 to $7 \mathrm{~m}$ and from 0 to $17 \mathrm{~m}$. They concluded that a short-period of strong fluctuations of the ground temperature reach a depth of about $1 \mathrm{~m}$ and, during summer time, the heat flux density transferred from the ground surface zone to the deeper part of ground was approximately 3.6W. $\mathrm{m}^{-2}$;

- Soil mosture: Ascion et al. [5] tested and concluded that the greatest energy performance could be obtained for wet soil by adopting a pipe's length by more than $50 \mathrm{~m}$, buried at a depth of $3 \mathrm{~m}$. Balghouthi et al. [6] carried out an experimental study on thermal and moisture behavior of dry and wet soil heated by buried capillary plaits on a prototype similar to an agricultural pipe greenhouse. It has been concluded that surface temperature amplitude was greater in wet soil than that of dry soil. Naylor et al. [7] presented results from a new monitoring network installed across a range of glaciated terrains in Indiana (USA). In situ, soil-moisture fluctuation results in a soil's thermal conductivity variability by an average of $27 \%$.

The consideration of these factors in the modeling of heat exchangers necessitates a great deal of work in the community. However, another model classifications encountered in the literature is proposed: taking into consideration the number of space variables used to solve the governing equations of the EAHE. Thus, models can be classified as one dimensional (1D), two dimensional (2D) and three dimensional (3D).

1D models were first used in the 1990s to establish a relation between a pipes inlet and outlet temperatures by Trombe et al. [8], Kabashinov et al. [9]. These models do not consider the horizontal variation of soil temperature due to the presence of EAHE pipes. However, the simplicity of calculation makes the models popular among engineers for estimating the pipe's length.

From the beginning of 2000, 2D models have been proposed. They are able to simulate a 2D soil temperature field at the cross section of an EAHE pipe and, thus, the thermal interaction between the pipe and its surrounding soil. Tittelein et al. [10] developed a 2D numerical model and tried to optimize its computational time with respect to existing 2D models. Kumar et al. [11] developed a $2 \mathrm{D}$ model using an artificial neural network and examined the effect of soil temperature gradient, surface conditions and moisture content. Hollmuller [12] developed a 2D analytical solution for cylindrical EAHE submitted to constant airflow, with harmonic temperature input and adiabatic or isothermal boundary conditions. Thiers et al. [13] developed a specific EAHE model including two submodels. The first, a soil thermal model, evaluated the soil temperature without EAHE influence. This soil temperature is supplied as a boundary condition to the second model, an EAHE thermal model, which calculates the outlet air temperature of the buried pipe.

In recent years, several 3D models have been proposed. They take into account the geometry of the EAHE's pipes. However, these models require a high computation power, leading to CPU times ranging, approximately, from one to several dozen hours. Kumar et al. [14] developed a finite difference model incorporating the effects of ground temperature gradient, surface conditions, moisture content and various design aspects of the earth-air heat exchanger (EAHE) and based on heat and mass transfer in the soil and circulating air. The model is in accordance with the predicted and experimental data, with an error of $1.6 \%$ for a length of piping of $80 \mathrm{~m}$. Bansal et al. [15] studied the effect of soil thermal conductivity on the thermal performance of an EAHE system with a 3D transient computational fluid dynamics (CFD) model. It was concluded that the energetic performance of the system is influenced by the ther- mal conductivity of soil, duration of operation and the pipe's length. Another 3D transient numerical model was used by Mathur et al. [16] to study the influence of thermo-physical properties of soil on the performance of an EAHE.

Despite the existence of many numerical models, presented above, all these models considered the soil surrounding the exchanger pipe as being homogenous. In reality, the majority of a EAHE's pipes are placed on a thin sand layer which retains the pipe's slope and the landfill soil around the exchanger pipe (coating soil) can also be different from the initial soil in order to retain the appropriate contact and, thus, the most appropriate thermal transfer between pipe and soil. Moreover, despite the fact that 3D models provide a more accurate description of an EAHE, the computational power needed to solve them remains considerable. Indeed, convection inside the pipe leads to well-known numerical instabilities which require small time increments. Consequently, efforts are still being made to improve the 3D numerical resolution of an EAHE. In this paper, a numerical model of an EAHE, which takes into account the heterogeneity of the soil surrounding the pipe, is proposed from a 2D numerical finite element model, virtually extended in the third direction by a coupling algorithm. Then, this model is validated with experimental data obtained with the geothermal platform at the University of Strasbourg, France. Finally, a typical EAHE configuration is modelled with three different coating soils along the entire pipe. Comparisons between different modeling results are carried out to study the impact of coating soil type on the energy performance of the EAHE system.

\section{Modeling the EAHE state}

\subsection{General modeling algorithm}

The general algorithm used here to find, numerically, the EAHE state is shown in Fig. 1. It is based on the calculation algorithm used by Trombe et al. [8] to determine the air outlet temperature $T_{\text {air, output }}$, but enriched by a numerical resolution of the $2 \mathrm{D}$ soil temperature field. The main assumption of this algorithm is that the temperature at the ground's surface $T_{\text {surf }}$ can be considered as constant when the loop over cross sections is browsed. Consequently, the state of the EAHE is obtained from two distinct, but imbricated, algorithms. The first aims at determining the temperature field in the soil (denoted $T_{\text {sol }}$ ) at time $t$, given the temperature at the ground's surface $T_{\text {surf }}(t)$. The second algorithm aims at calculating (at constant $T_{\text {surf }}$ ) the heat exchange between the air flowing inside the exchanger and the ground, over its entire length in order to deduce the air outlet temperature. The two next sections are devoted to a more precise description of these two models.

\subsection{Modeling of the temperature field in the surrounding soil}

Fig. 2 shows a schematic representation of a vertical cross section of the EAHE, in which several kinds of soil-type materials are introduced:

Vegetal soil: representing the topsoil at the surface. Some parts of this soil were obviously disturbed during the excavation phase of the EAHE;

Earth: it is the natural soil present on the construction site. It was likewise disturbed;

- Coating soil: it is the landfill soil surrounding the exchanger along its entire length;

- Stabilizer sand: thin layer of sand to maintain the slope of the pipe. 


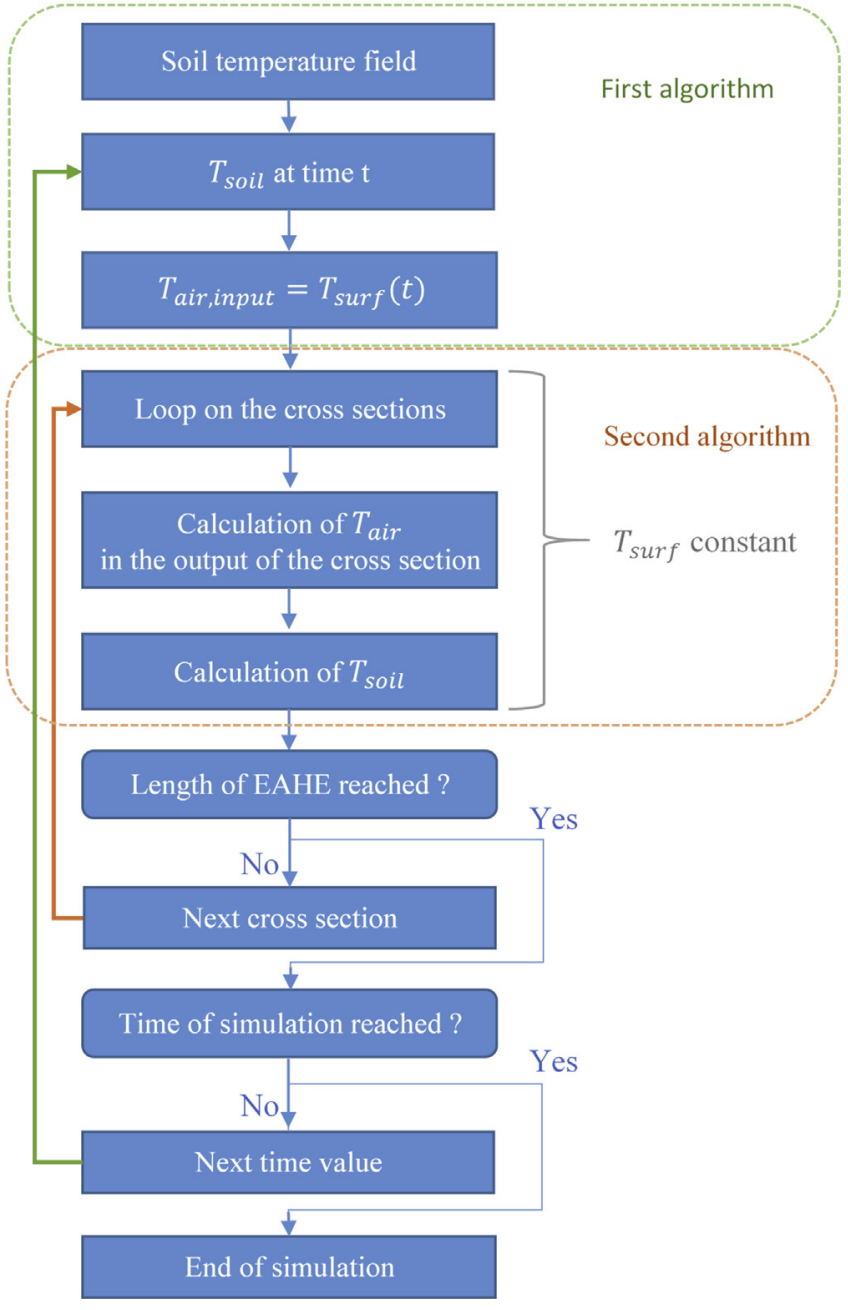

Fig. 1. General algorithm used to find the state of the EAHE.

Despite the fact that the vegetal soil and the earth have been disturbed during the excavation phase of the EAHE, no distinction between disturbed and undisturbed soils has been considered in the calculations. The 2D temperature field in the vertical cross section is obtained by solving the heat equation using the finite element method. In this study, the French general-purpose finite element software Code Aster ${ }^{\circledR}$ has been used. The mesh of the cross section is made of three-node triangle elements and is refined around the pipe to improve the calculation accuracy (see Fig. 3). On the contrary, the element size becomes more significant close to the bottom of the mesh to save CPU time. Boundary conditions are the following:

- $\mathrm{T}_{\text {surf }}$ : the temperature at the ground's surface is given on the upper boundary;

- $\mathrm{T}_{\mathrm{air}}$ : the temperature of the air is given on the pipe's wall;

- $\mathrm{T}_{\text {geo }}$ : the (constant in time) geothermal temperature is given by the bottom boundary;

- $\varphi_{1}$ and $\varphi_{r}$ : thermal flow on the lateral boundaries are assumed to be zero.

The convective heat transfer between pipe and air is assumed to be governed by a constant convective coefficient $h_{a}$. The initial temperature field is obtained by a stationary calculation obtained with the value $T_{\text {surf }}(t=0)$. Concerning numerical aspects, the linear system which gives the increment of nodal temperatures is obtained from an Euler-implicit scheme with a time increment corresponding to a 20 min interval between two measurements.

\subsection{Modeling of air temperature inside the EAHE}

The modeling of air temperature in the exchanger is a complex problem to solve because it depends on many parameters (Thiers et al. [13]): the outside temperature, thermo-physical properties of soil and air, air velocity and exchanger geometry. These parameters characterize the heat transfer taking place in the soil between the ground and air circulating in the exchanger. As previously suggested, heat transfer in the soil is rather slow as compared to the circulation of air because of thermal damping soil and the frequency of thermal excitations at the soil's surface. For example, daily thermal excitations have an impact on the first $60 \mathrm{~cm}$ below the surface. For a very short duration, e.g. the time taken by the air to browse the length of the exchanger, the temperature field in the soil can be considered as constant. Thus, this is considered to be the temperature along the pipe. Consequently, the thermal exchange between the

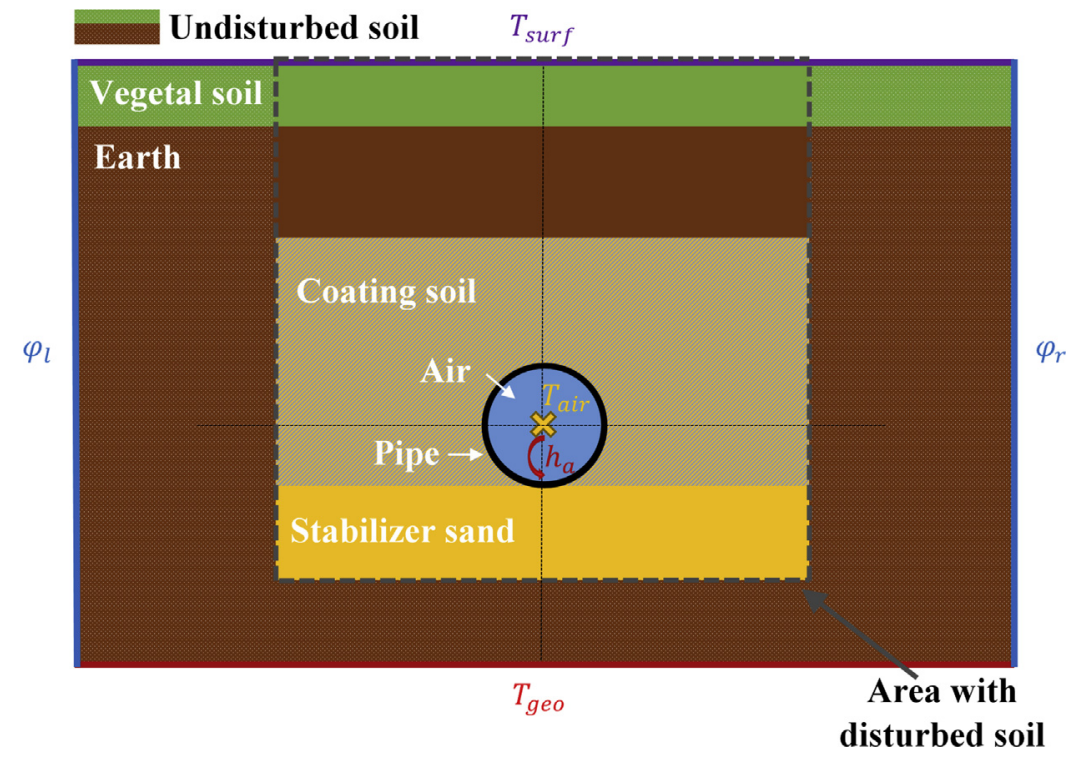

Fig. 2. Schematic view of a vertical cross section of the EAHE. The scheme's scale is not realistic. 


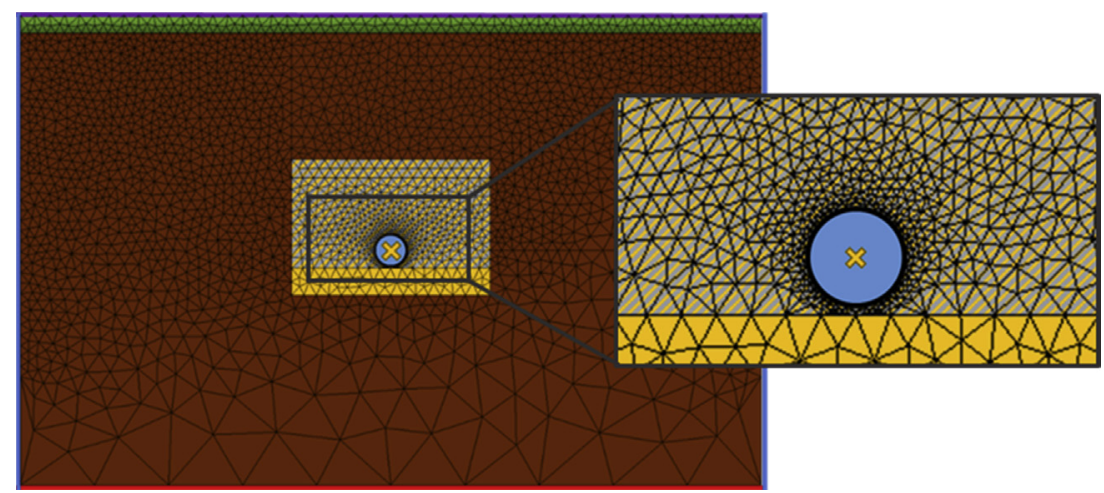

Fig. 3. 2D mesh used to find the temperature field in the different soils.

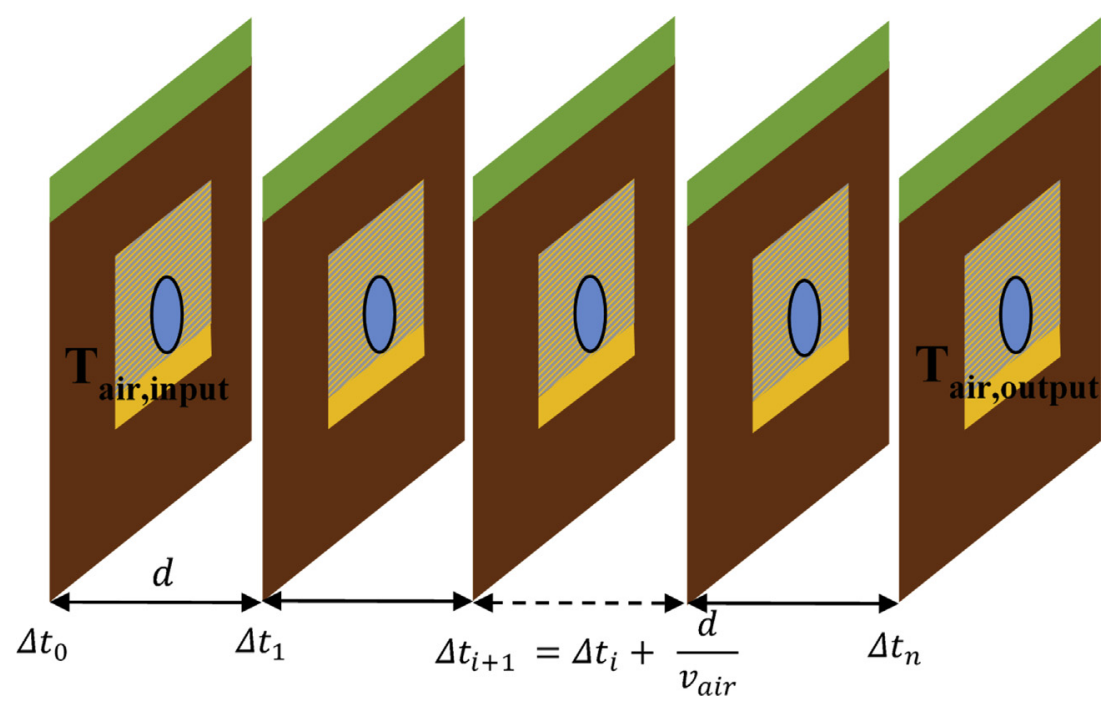

Fig. 4. Principle of the method for calculating the air temperature of the air leaving the earth-air exchanger.

pipe and air inside the pipe is calculated by the transient linear thermal 2D model described in the previous section. The latter is solved using the constant temperature of the ground's surface during the time corresponding to the distance crossed by the air flowing in the heat exchanger, as illustrated in Fig. 4 (about $0.2 \mathrm{~s}$ ). To simplify the model, the pressure losses are neglected, and air velocity is constant in time and over the entire length of the exchanger.

\section{Model validation with experimental data}

\subsection{Presentation of the experimental geothermal platform}

The geothermal platform used to carry out the experiments is located on site at the I.U.T. Robert Schuman, University of Strasbourg, France. The EAHE is divided into three portions with different types of coating soils: (1) sand, (2) a mix between sand and bentonite (3\%), and (3) initial earth soil. Each part is associated with a vertical section in which temperature is measured numbered from 1 to 3, respectively: sand; sand-bent; and earth (see Fig. 5).

More precisely, six temperature sensors (PT100) are present in each section in accordance with the green cross in Fig. 6 . The numbering of sensors is in ascending order: the greater the index, the greater the distance from the pipe. They provide temperature values with an uncertainty of $0.1^{\circ} \mathrm{C}$. The air temperature inside the pipe is measured at five different locations: at the input of the pipe in sections $1-3$, and at the output of the pipe. Further, the air velocity is controlled by a fan at the outlet of the exchanger;
Table 1

Characteristics of EAHE portions and their vertical sections.

\begin{tabular}{llll}
\hline EAHE portion & $\begin{array}{l}\text { Numeration of } \\
\text { the associated } \\
\text { vertical section }\end{array}$ & Depth $z[\mathrm{~m}]$ & $\begin{array}{l}\text { Length of the } \\
\text { exchanger }[\mathrm{m}]\end{array}$ \\
\hline $\begin{array}{l}\text { Sand } \\
\begin{array}{c}\text { Sand \& bentonite } \\
\quad \text { sand-bent) }\end{array}\end{array}$ & 1 & $0.73 \pm 0.02$ & $10.40 \pm 0.01$ \\
Earth & 3 & $0.92 \pm 0.02$ & $10.40 \pm 0.01$ \\
\hline
\end{tabular}

this fan allows the maintaining of the air velocity which is constant during temperature recording. The uncertainty on the velocity is $0.2 \mathrm{~m} . \mathrm{s}^{-1}$. The recording is performed by a data acquisition (Keithley), every $20 \mathrm{~min}$. Finally, soil moisture $\left(H R_{\text {soil }}\right)$ for the coating soil and the stabilizer sand is measured in sections 1-3 with a probe located at the boundary between these two materials, as shown in Fig. 6. The measurement uncertainty of soil moisture is $3 \%$.

Finally, it must be remembered that the installation of a pipe system requires a regular slope of $2 \%$. Thus, the well depth varies according to the values in Table 1.

\subsection{Determining of the soil's thermal properties}

The thermo-physical properties of the soil - conductivity, density and the specific heat allowing the calculation of the thermal diffusivity - are identified using different methods: experimental measurements realized in our laboratory; literature values; and 


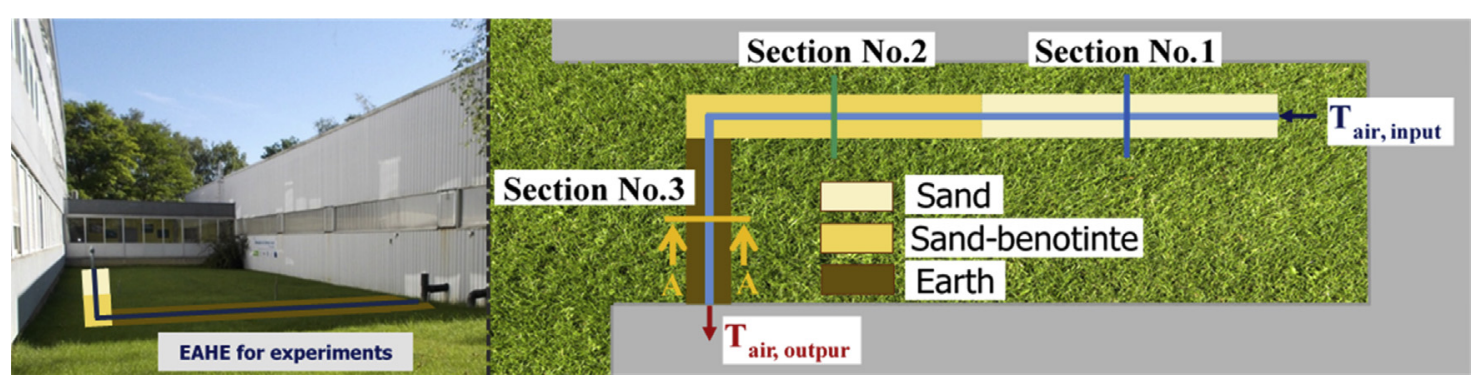

Fig. 5. Picture and sky view representation of the EAHE experiment.

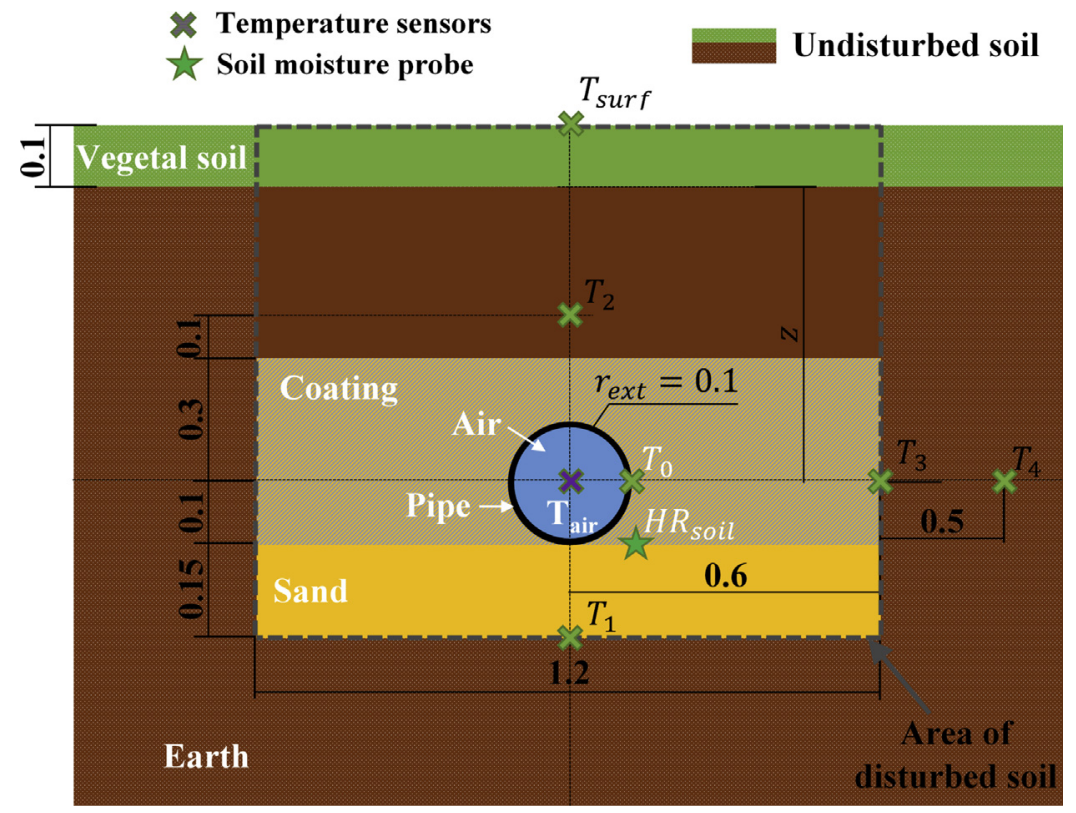

Fig. 6. Schematic A-A cross section mentioned in Fig. 7. All dimensions are in meters. The scheme's scale is not realistic.
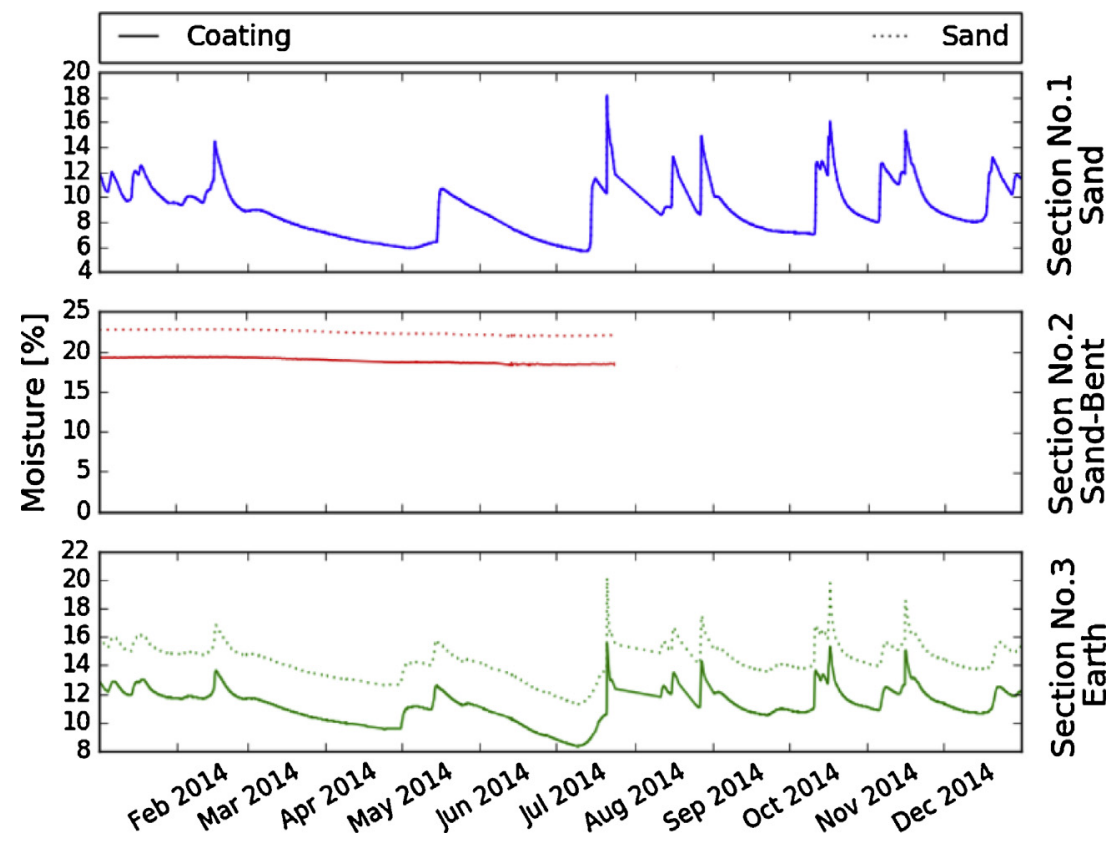

Fig. 7. Variation in soil moisture content during the study. 


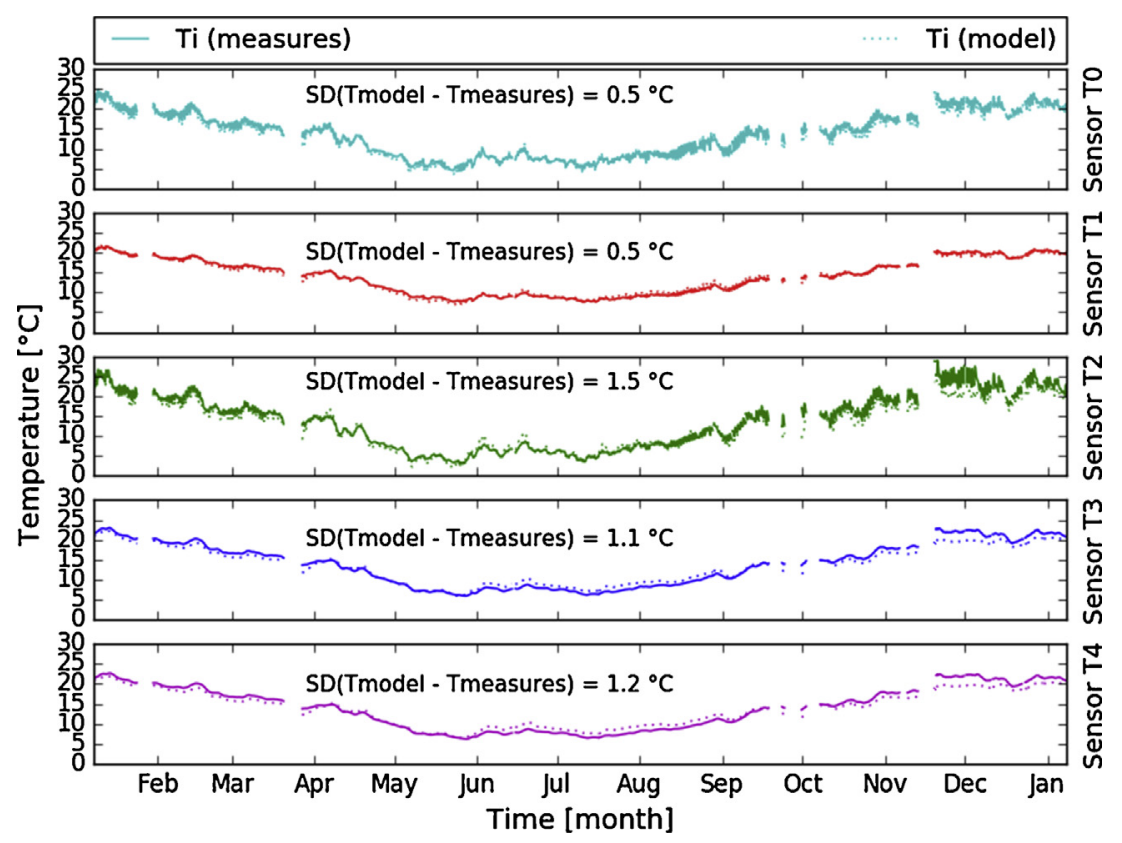

Fig. 8. Temperature evolution for the probes obtained by modeling and measurements for section 1 (sand). The notation SD stands for "standard deviation".

Table 2

Thermal diffusivity $\left[\mathrm{mm}^{2} \cdot \mathrm{s}^{-1}\right]$ of the different materials.

\begin{tabular}{llll}
\hline Section No. & 1 & 2 & 3 \\
\hline Vegetal soil & $0.58 \pm 0.06$ & & \\
Coating & $0.63 \pm 0.08$ (sand) & $0.67 \pm 0.08$ (sand-bent) & $0.71 \pm 0.07$ (earth) \\
Sand & $0.63 \pm 0.08$ & $0.85 \pm 0.06$ & $0.74 \pm 0.08$ \\
Earth & $0.72 \pm 0.04$ & & \\
Pipe & $0.28 \pm 0.01$ & & \\
\hline
\end{tabular}

identification. Nowamooz et al. [17] studied the influence of soil moisture on the thermo-physical properties for the two following soils: pure sand and clay. The same method is used to measure thermo-physical properties of the mix between bentonite (3\%) and sand. Below, the value of thermal diffusivity for a given moisture $H R_{\text {soil }}$ is determined by linear interpolation of the previous experimental data. Since the soil moisture was measured in 2014 (see Fig. 7), it was possible to calculate the diffusivities of, both, sand and coating soil. In July 2014, following power surge, $H R_{\text {soil }}$ the probe in section 2 was not functional and measures for this period were discarded. The considered diffusivity values correspond to an average calculated over 2014.

The thermal diffusivity of the pipe was obtained from the technical paper supplier. Concerning the diffusivity of the earth, no value was available in the literature to our knowledge. That is why it was obtained using an identification method between the model and measurements. The fit, of least squares, was obtained by using the well-known Levenberg-Marquardt method. Finally, the entire set of diffusivity values of the different materials is summarized in Table 2, in which the variability accounts for experimental uncertainty over the averaging period.

\subsection{Validation of the soil's temperature measurements}

The model of soil is simulated for sections 1,2 and 3 , for the year 2014. The model's results are compared with the experimental data at the respective locations of probes $T_{0}, T_{1}, T_{2}, T_{3}$, and $T_{4}$ (see Fig. 8). The comparison is represented in two graphs: one graph representing the temperature of the probe as a function of time annotated with standard deviation SD (Figs. 8, 10 and 12) and another representing the statistical distribution of the differences between temperature probes per $0.1{ }^{\circ} \mathrm{C}$ (Figs. 9, 11 and 13).

Figs. 8, 10, and 12 provide information on the model's thermal behavior. Temperature fluctuations of the sensor $T_{2}$ show air temperature variations on the surface, taken into account by the model. This remark also applies to the probe $T_{0}$. The temperature of the soil near the exchanger ( $T_{0}$ probe) is concerned with temperature variations of air flowing into the exchanger. In addition, temperature fluctuations in the soil are damped with depth. The role of soil as thermal damping is reproduced by the model.

Data in Figs. 9, 11, and 13 quantify the thermal behavior of the model relative to the measurements. The maximum difference for the sensor $T_{2}$ is about $4{ }^{\circ} \mathrm{C}$. This range can be explained by thermal phenomena neglected at the soil surface, such as solar radiation. The shape of the histogram's error, for sensors $T_{3}$ and $T_{4}$, are similar, with a maximum of $3{ }^{\circ} \mathrm{C}$. So, concerning probes $T_{0}$ and $T_{1}$, the maximum difference of $1.5^{\circ} \mathrm{C}$ is less important.

To summarize, the temperature differences between the model and the measurements are reduced by approaching the exchanger.

\subsection{Validation of air temperature}

As previously described, measurements of air temperature is carried out at five locations: pipe's input; section 1 (sand); section 2 (sand-bent); section 3 (earth); and at the pipe's output. To validate our model and check the temperature of the measurement points, the exchanger is divided into six slices, as shown schematically in Fig. 14. The previous finite elements model is run in each slice by imposing the temperature of the input air during the period between January and July 2014.

The air temperature obtained by the model and the experimental exchanger are compared using two graphs: one graph illustrates temperature air evolution annotated with standard deviation SD (see Figs. 15 and 17) and the second represents a statistical distribution of the temperature difference between the model and measurements with intervals of $0.1^{\circ} \mathrm{C}$ (Figs. 16 and 18).

Figs. 15 and 17 show the similarity of temperature variations between the model and the measurements. A temperature differ- 


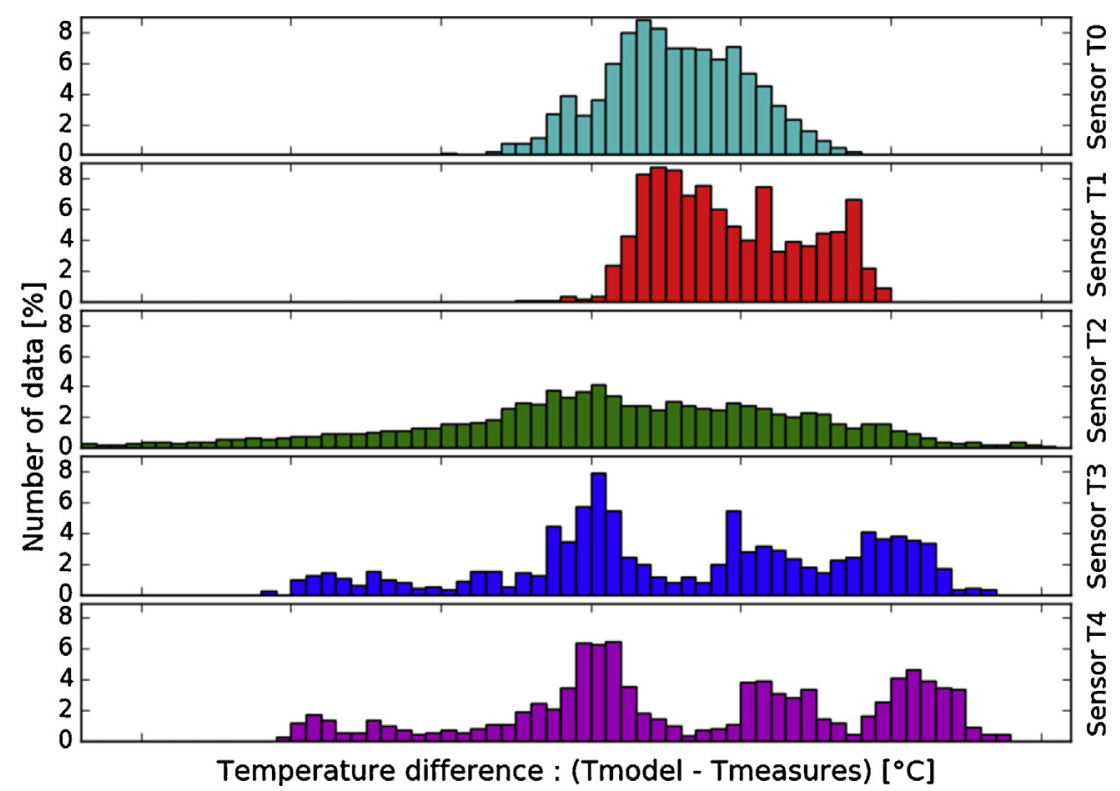

Fig. 9. Distribution statistics of temperature differences of probes for section 1 (sand).

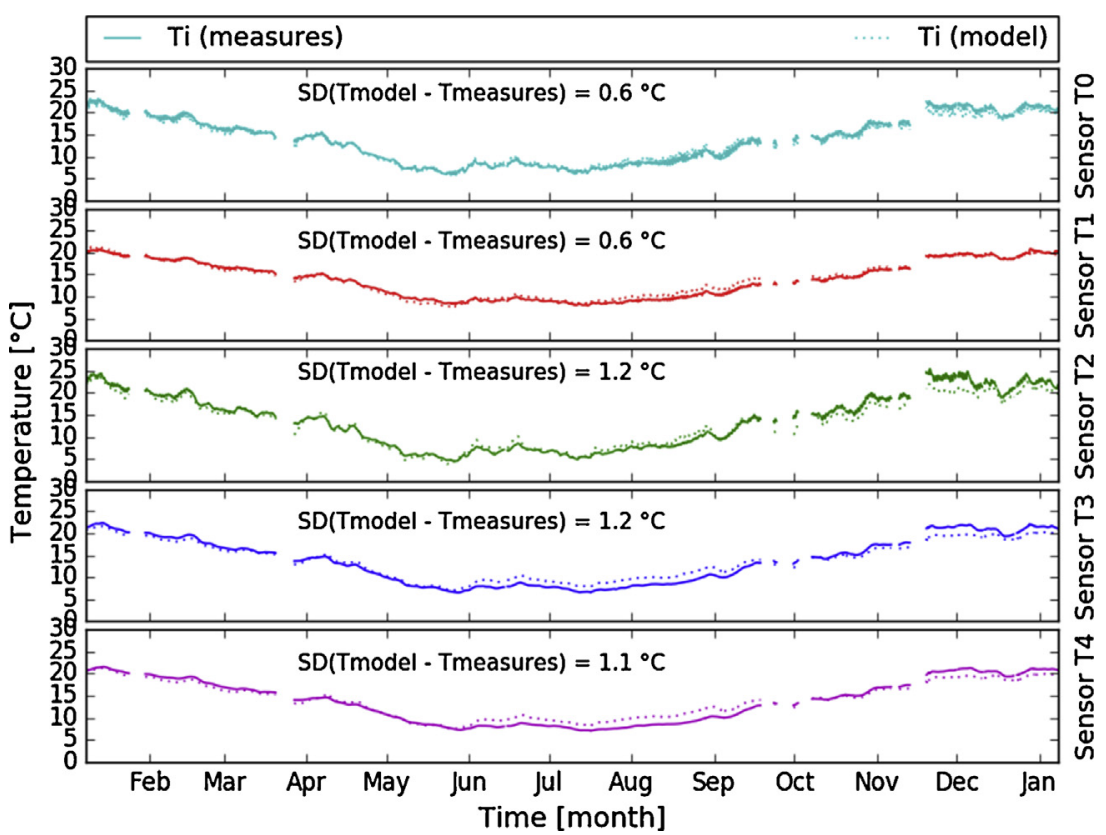

Fig. 10. Temperature evolution for the probes obtained by modeling and measurements for section 2 (sand-bent). The notation SD stands for "standard deviation".

ence is visible for section 2 (sand-bent), leading to an increase in this difference for the next sections. In addition, the maximum difference between the model and the measurements is $1.9^{\circ} \mathrm{C}$ in January and of $3.6^{\circ} \mathrm{C}$ in July. The maximum error in the summer can be explained by the fact that temperature amplitudes are higher in summer than in winter. Systematic error is due to an underestimation of heat exchange between the air flowing through the exchanger and the ground.

Statistical distribution of temperature differences between the model and measurements quantify the errors of the model. First, the extent of the difference increases with the distance covered by the air. For the two simulated months, they are similar to a maximum extent of $4^{\circ} \mathrm{C}$. Differences are centered at $0^{\circ} \mathrm{C}$ for section 1 (sand) but a recurring difference shifts the center by $1^{\circ} \mathrm{C}$ at the exchanger's output.

\subsection{Precision of numerical model with a sensitivity study}

To investigate the impact of input parameters variability on the cooling/heating energy, a sensitivity analysis has been carried out. Consequently, the entire EAHE model has been run by varying each input parameter around a set of reference values (given in Table 3 ). The considered relative variations are $-10 \%,-5 \%,+5 \%$ and $+10 \%$ and are considered sufficiently significant to maximize the possible experimental uncertainty cumulated with the time variability. Simulations cover the month of January and the month of July 2014. The results of the sensitivity study, shown in Figs. 19 and 20, are interpreted by a graphical representation of the heating energy in January and cooling energy in July, depending on the parameter's value. These are translated into a percentage of variation with respect to the reference case. For both cases, the parameters 


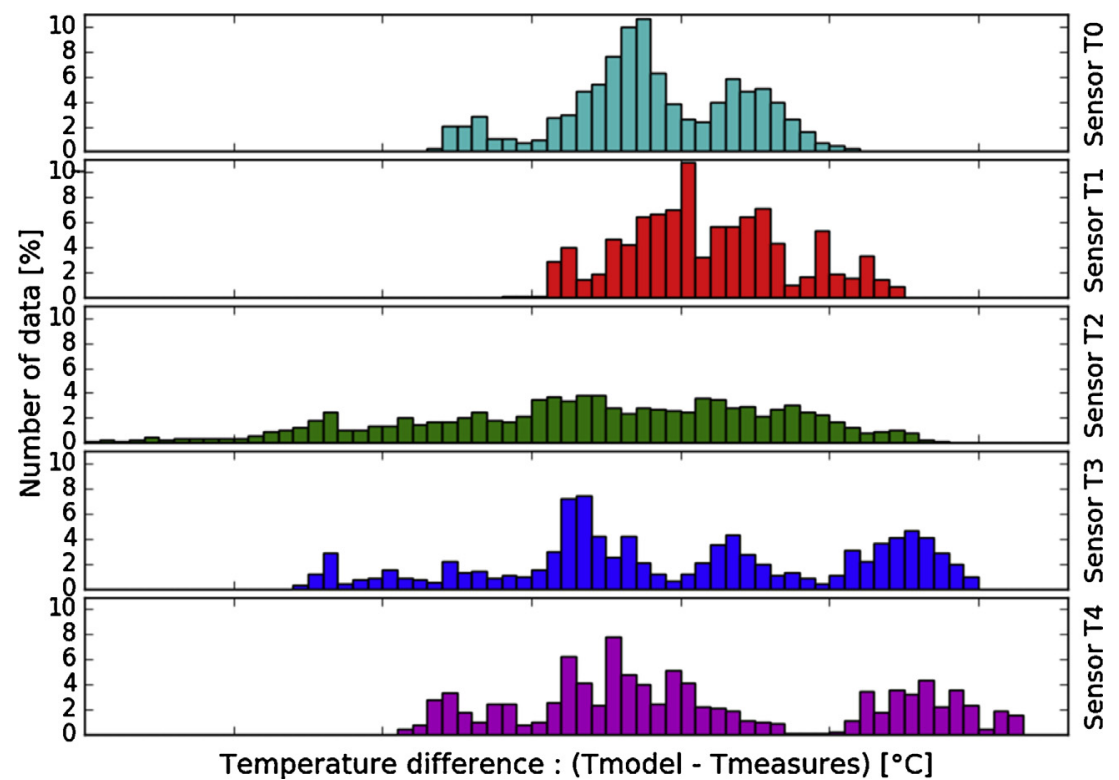

Fig. 11. Distribution statistics of temperature differences of probes for section 2 (sand-bent).

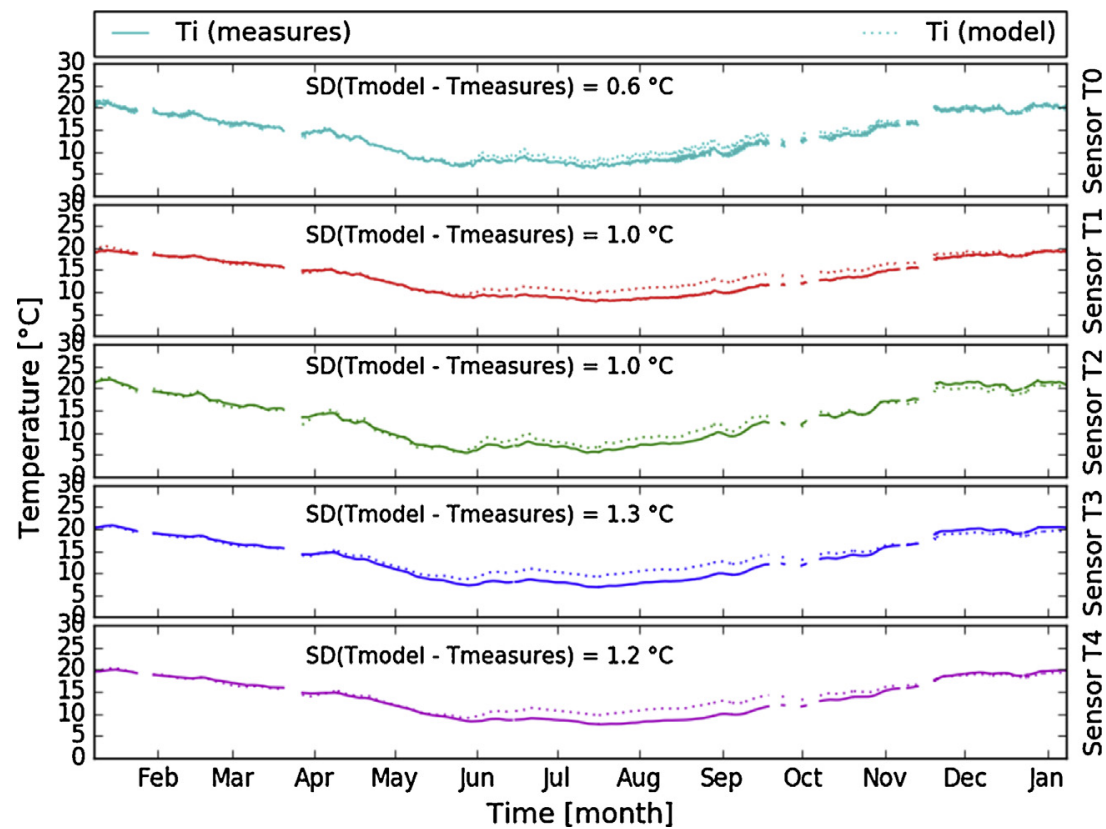

Fig. 12. Temperature evolution for the probes obtained by modeling and measurements for section 3 (earth). The notation SD stands for "standard deviation".

Table 3

Parameters' reference values used for the sensitivity study.

Factors

thermal conductivity of soil for coating

volumetric heat capacity of soil for coating

thermal conductivity of sand stabilizer

volumetric heat capacity of sand stabilizer

thermal conductivity of soil

volumetric heat capacity of soil

thermal conductivity of pipe

volumetric heat capacity of pipe

convective heat exchange coefficient

velocity of air flowing in the exchanger

depth of exchanger

length of exchanger

$\begin{array}{ll}\text { Parameters } & \text { Values } \\ \lambda_{\text {coating }} & 1.14 \\ \mathrm{C}_{\text {coating }} & 1.60 \\ \lambda_{\text {sand }} & 1.34 \\ C_{\text {sand }} & 1.81 \\ \lambda_{\text {soil }} & 1.14 \\ C_{\text {soil }} & 1.61 \\ \lambda_{\text {pipe }} & 0.500 \\ C_{\text {pipe }} & 1.76 \\ h_{\text {conv }} & 10.0 \\ v_{\text {air }} & 2.50 \\ z & 1.00 \\ L & 30.0\end{array}$

Unit

$\mathrm{W} \cdot \mathrm{m}^{-1} \cdot \mathrm{K}^{-1}$

MJ.K. $\mathrm{K}^{-1} \cdot \mathrm{kg}^{-1}$

W. $\mathrm{m}^{-1} \cdot \mathrm{K}^{-1}$

MJ. $\mathrm{K}^{-1} \cdot \mathrm{kg}^{-1}$

W. $m^{-1} \cdot K^{-1}$

MJ.K $K^{-1} \cdot \mathrm{kg}^{-1}$

W. $m^{-1} \cdot K^{-1}$

$M J \cdot K^{-1} \cdot \mathrm{kg}^{-1}$

W. $m^{-2} \cdot K^{-1}$

$m . s^{-1}$

$m$

m 


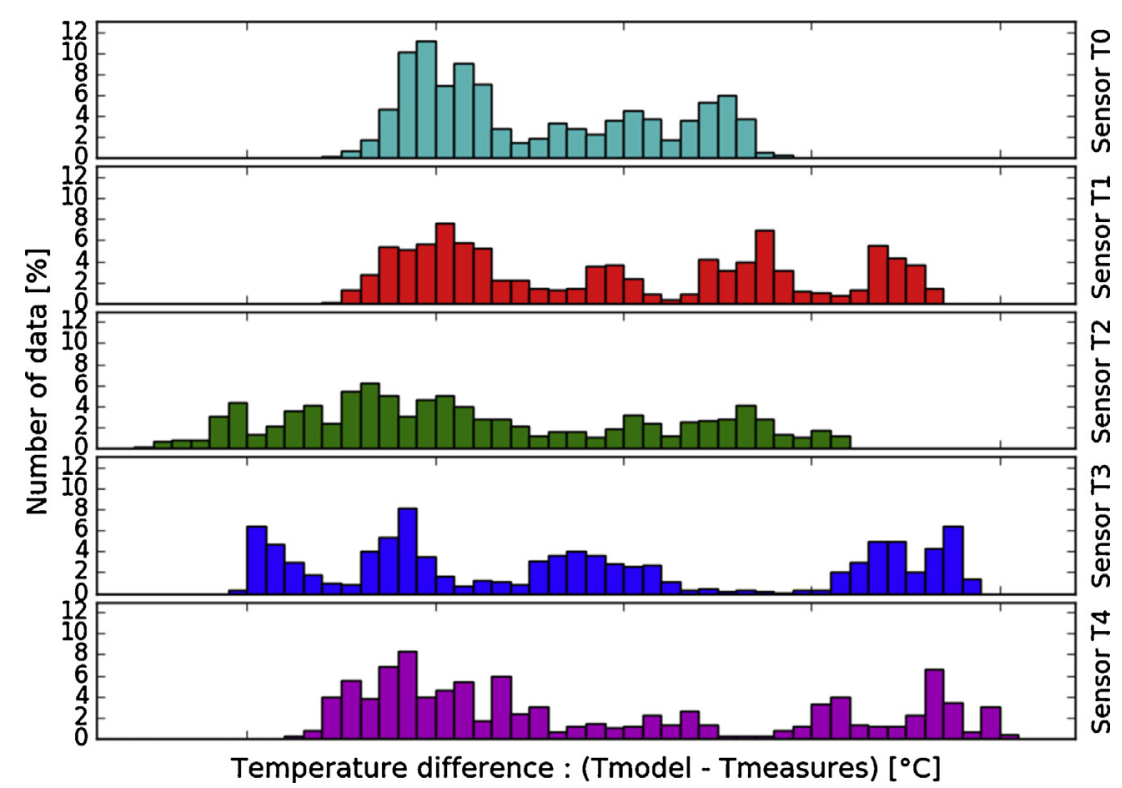

Fig. 13. Distribution statistics of temperature differences of probes for section 3 (earth).

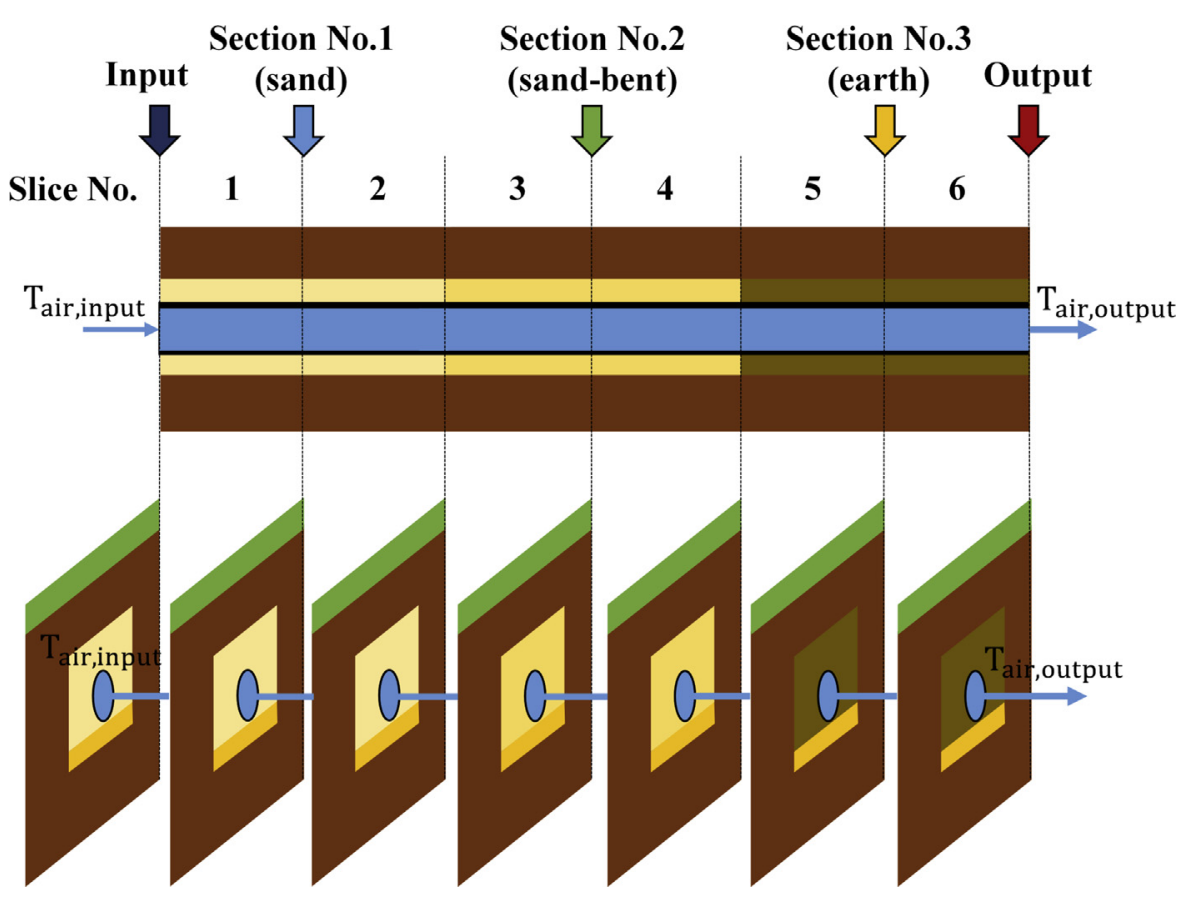

Fig. 14. Schematic view of the numerical method used to find the thermal state of the EAHE.

Table 4

Influence of parameter uncertainty on model uncertainty.

\begin{tabular}{|c|c|c|c|c|c|c|c|c|c|c|c|c|c|}
\hline Parameter & & $\lambda_{\text {coating }}$ & $C_{\text {coating }}$ & $\lambda_{\text {sand }}$ & $C_{\text {sand }}$ & $\lambda_{\text {soil }}$ & $C_{\text {soil }}$ & $\lambda_{\text {pipe }}$ & $C_{\text {pipe }}$ & $h_{\text {conv }}$ & $v_{\text {air }}$ & $z$ & $L$ \\
\hline Parameter uncertainty [\%] & & 10 & 10 & 10 & 10 & 6 & 10 & 4 & 4 & 2 & 1.5 & 2 & 0.1 \\
\hline \multirow[t]{2}{*}{ Model uncertainty [\%] } & January & 1.8 & 0.5 & 1.7 & 0.2 & 0.8 & 1.4 & 1 & 0.2 & 0.4 & 1.8 & 2 & 0.1 \\
\hline & July & 1.8 & 0.8 & 0.5 & 0.2 & 0.6 & 0.2 & 0.1 & 0.1 & 0.4 & 1.8 & 1 & 0.1 \\
\hline
\end{tabular}

of the air velocity and depth of the EAHE are the most sensitive of the model's parameters. Other parameters influence results by less than $2 \%$. Based on these results, it can be concluded that, for a defined configuration, accurate estimates of exchanger depth and air velocity in the heat exchanger are necessary. This observation is in accordance with the present situation because the uncertainty on the pipe's depth and on air velocity is found to be much lower than the uncertainty of the soil's thermal properties. As shown in Table 4, the uncertainty of the prediction results is less than $2 \%$ if we take into account the real measurement uncertainty of various parameters.

Despite little variation of prediction results due to the variation of different parameters, it must be remembered that the real variation range of the soil's thermal properties is much greater than 


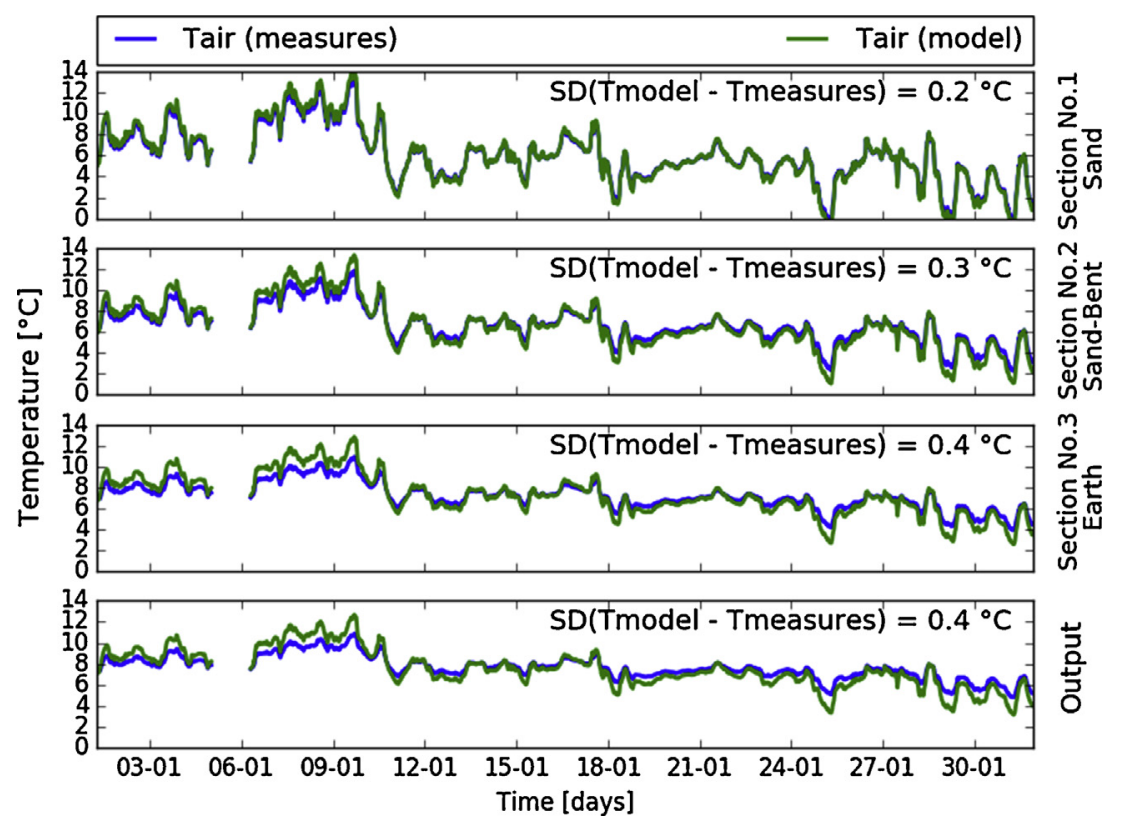

Fig. 15. Air temperature of the heat exchanger at different locations for January 2014. The notation SD stands for "standard deviation".

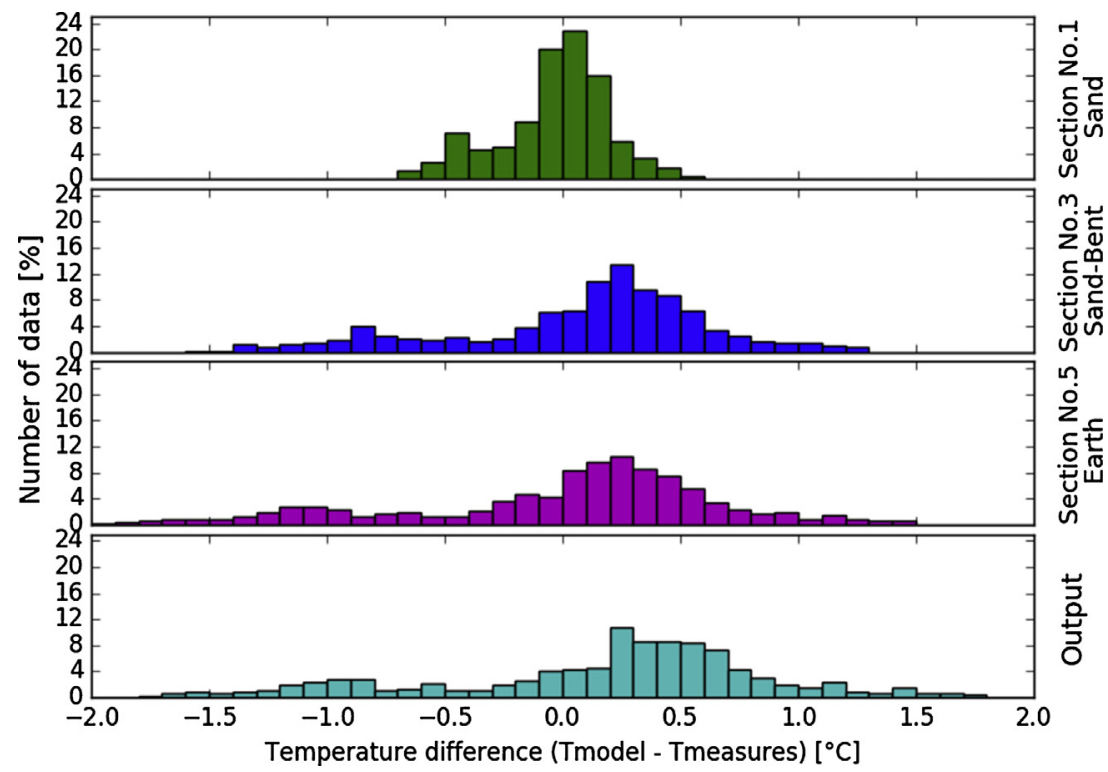

Fig. 16. Statistical distribution of air temperature difference between the model and measurements for January 2014.

the $10 \%$ used in our sensitivity study. A broader investigation of the impact of coating soil is presented in the next section.

\section{The study of the impact of different coating soil types}

In order to investigate the influence of different soil types for coating on an EAHE's energy performance, a typical exchanger configuration is considered with three soil types for coating the entire exchanger pipe at two extreme moistures, measured in 2014. Each case is simulated with the model presented previously for the month of January and the month of July 2014.

The common characteristics of the exchanger are: a buried depth of $75 \mathrm{~cm} ; 30 \mathrm{~m}$ in length; and an air speed of $4.0 \mathrm{~m} . \mathrm{s}^{-1}$ (represented in Fig. 21):
Table 5

Thermal properties of coating soils with maximal and minimal measured soil moisture, for 2014.

\begin{tabular}{llllll}
\hline Type of soil & $H R$ & {$[\%]$} & $\lambda\left[W \cdot m^{-1} \cdot K^{-1}\right]$ & $\left.C[M] \cdot K^{-1} \cdot m^{-3}\right]$ & $a\left[\mathrm{~mm}^{2} \cdot s^{-1}\right]$ \\
\hline \multirow{2}{*}{ Sand } & $\min$ & 5.63 & 0.80 & 1.44 & 0.56 \\
& $\max$ & 17.0 & 1.49 & 1.84 & 0.81 \\
\multirow{2}{*}{ Sand-bent } & $\min$ & 18.4 & 1.38 & 2.05 & 0.67 \\
\multirow{3}{*}{ Earth } & $\max$ & 19.5 & 1.43 & 2.11 & 0.68 \\
& $\min$ & 8.4 & 0.95 & 1.36 & 0.70 \\
& $\max$ & 16.6 & 1.45 & 1.68 & 0.86 \\
\hline
\end{tabular}

\subsection{Overview of the studied soil types}

The thermal properties of soils used for the simulations are those of soils used in the experimental site with extreme moisture measured during the period of 2014 (see Table 5). An interesting point 

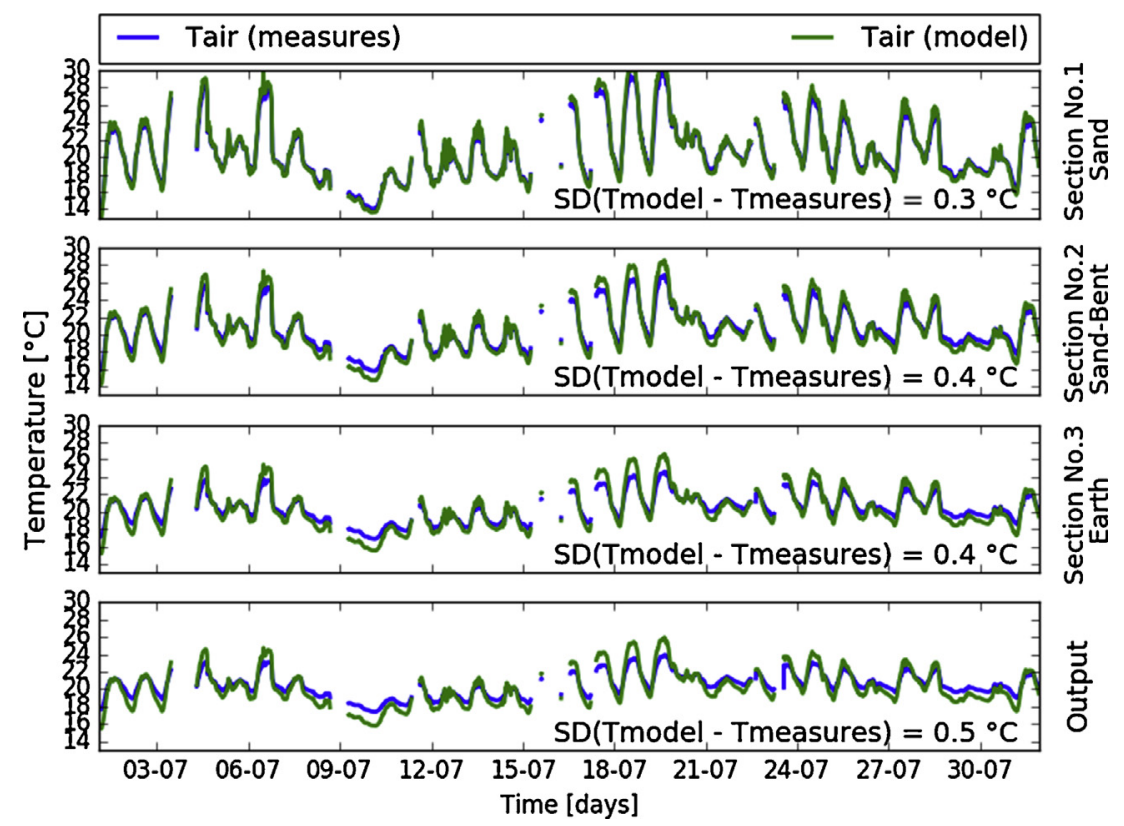

\section{蒙}

Fig. 17. Air temperature of the heat exchanger at different locations for July 2014. The notation SD stands for "standard deviation".

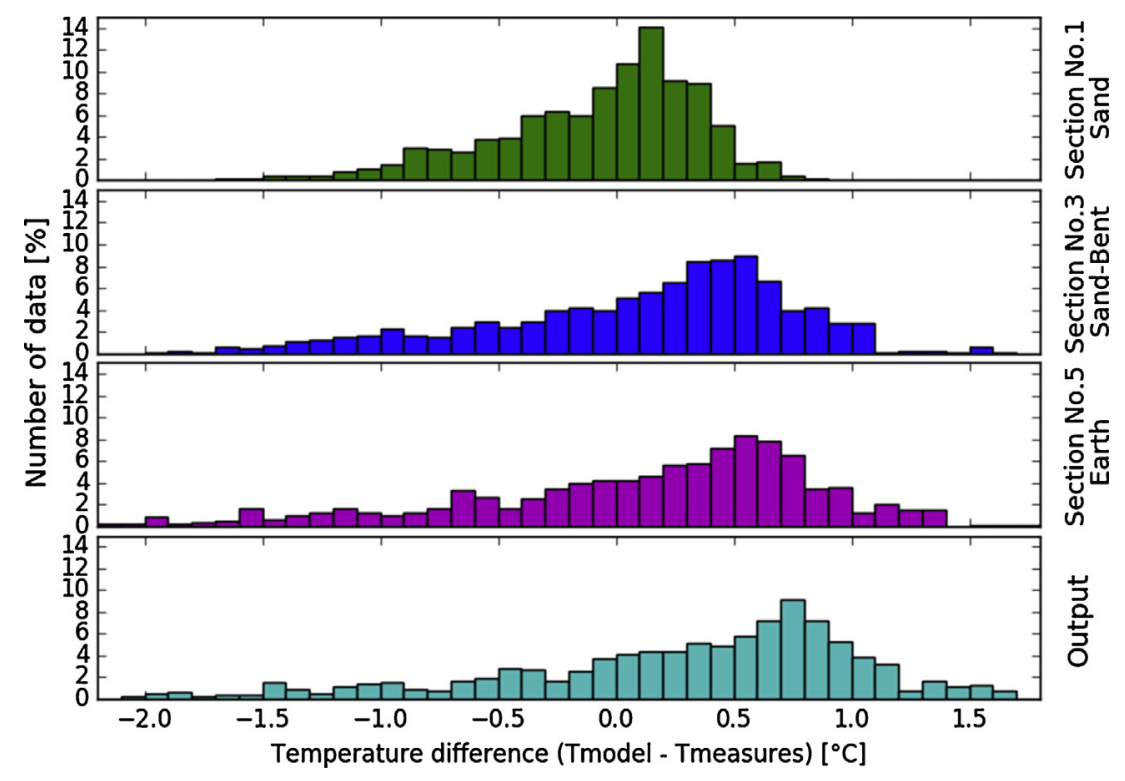

Fig. 18. Statistical distribution of air temperature difference between the model and measurements for July 2014.

is the ability of the mix, between sand and bentonite, to sustain a quasi-constant high moisture content. It has a higher density, higher thermal conductivity and higher specific heat than the other soils.

\subsection{Comparison of EAHE's thermal performance}

The thermal performance of heat is evaluated by using the following relation:

$E=\int \phi(t) d t$

where $\Phi(t)$ is the power of the heat exchange at each moment in time $t$. It is obtained by:

$\Phi(t)=v_{\text {air }} \times \pi \times r_{\text {int }}^{2} \times c_{p, \text { air }} \times\left[T_{\text {air,input }}(t)-T_{\text {air,output }}(t)\right]$
Table 6

Heating energy of the EAHE system, for January 2014.

\begin{tabular}{llll}
\hline Soil type & $\begin{array}{l}\text { Minimal } \\
\text { moisture }[k W h]\end{array}$ & $\begin{array}{l}\text { Maximum } \\
\text { moisture }[k W h]\end{array}$ & Difference [\%] \\
\hline Sand & 60.47 & 71.90 & 15.90 \\
Sand-bent & 73.18 & 74.04 & 1.16 \\
Earth & 65.26 & 72.68 & 10.21 \\
Maximum difference [\%] & 17.37 & 2.89 & \\
\hline
\end{tabular}

in which $v_{\text {air }}$ represents flowing air speed, $r_{\text {int }}$ represents the inner radius of the exchanger pipe, $c_{p \text {,air }}$ represents the heat capacity of air, $T_{\text {air,input }}$ represents input air temperature and $T_{\text {air,output }}$ represents output air temperature. If $E>0$ ( $E<0$, respectively) the energy is qualified "heating energy" $E_{h}$ (cooling energy $E_{c}$, respectively). In the winter, January 2014, only heating energy was measured and the results are given in the Table 6. In the summer, 


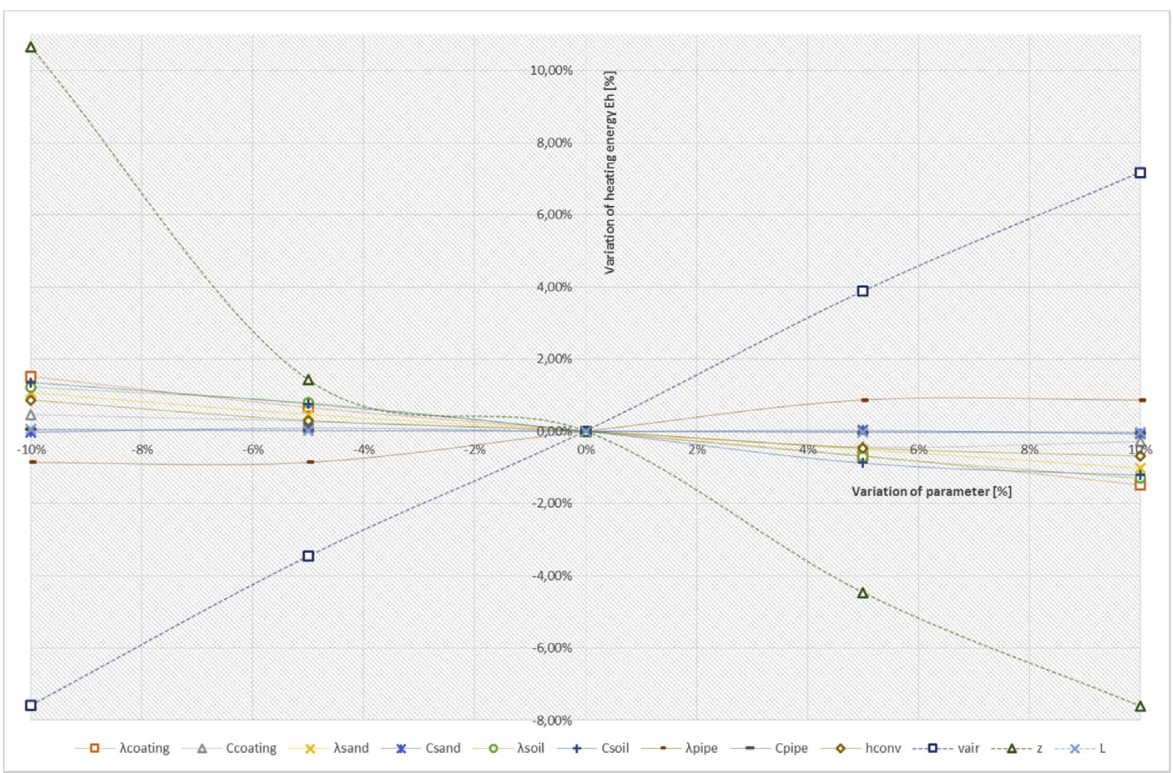

Fig. 19. Graphical representation of the variation of heating energy depending on the variation of a parameter, for the month of January.

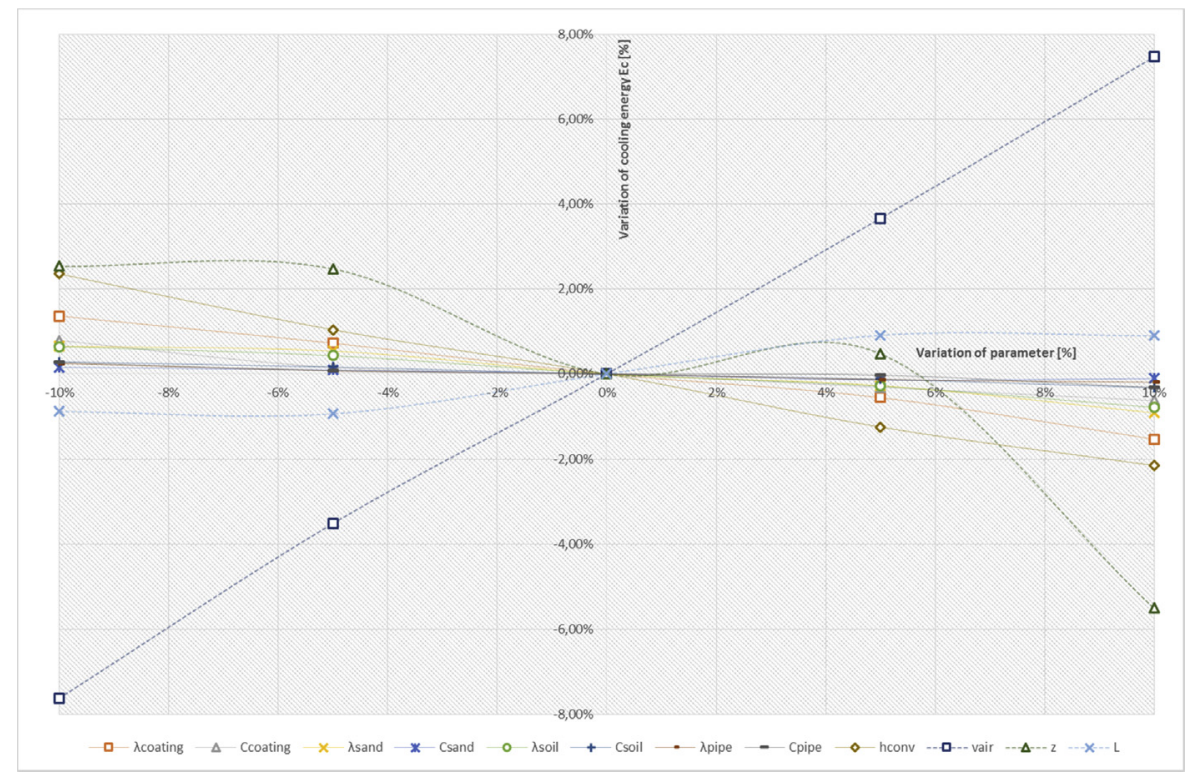

Fig. 20. Graphical representation of the variation of cooling energy in depending on the variation of a parameter, for the month of July.

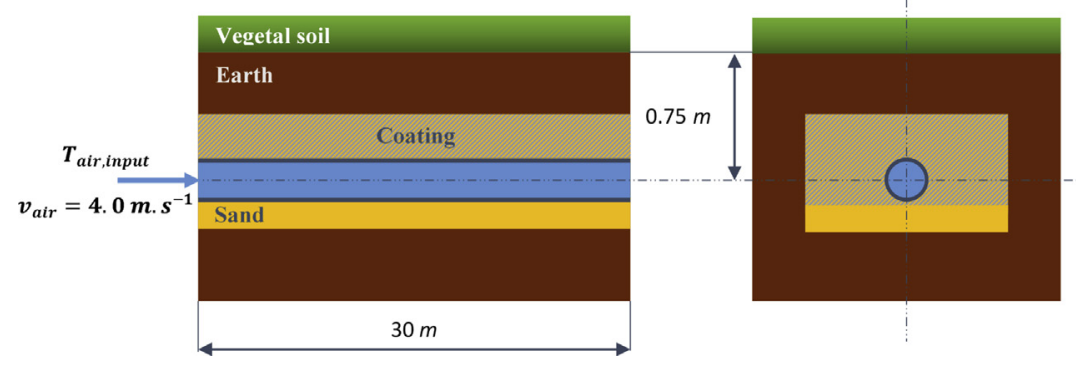

Fig. 21. Virtual exchanger's characteristic.

July 2014, cooling energy was measured and the results are summarized in Table 7. The results of the recovered energy is interpreted by analyzing the results in Tables 6 and 7, either by column or by row. For a given type of soil, humidity has an influence on exchanged energy for both simulation periods. For the sand, the difference in exchanged energy was $15.9 \%$ in January and $13.6 \%$ in July. For the earth, it was $10.2 \%$ in January and $9.1 \%$ in July. For the mix, it was $1.2 \%$ in January and $0.8 \%$ in July. Interestingly, the relative energy 
Table 7

Cooling energy of the EAHE system, for July 2014.

\begin{tabular}{llll}
\hline Soil type & $\begin{array}{l}\text { Minimal } \\
\text { moisture }[k W h]\end{array}$ & $\begin{array}{l}\text { Maximum } \\
\text { moisture }[k W h]\end{array}$ & Difference [\%] \\
\hline Sand & 46.85 & 54.23 & 13.61 \\
Sand-bent & 54.84 & 55.28 & 0.80 \\
Earth & 49.27 & 54.22 & 9.13 \\
Maximum difference [\%] & 14.57 & 1.92 & \\
\hline
\end{tabular}

increases for the two periods and that increase is quite similar even if the absolute value of the energy is different for the two periods. It has been concluded that the soil moisture content for the coating may have a significant impact on energy for heating and cooling. For the same humidity in the soil for the coating, the exchanged energy as a function of soil type depends on the value of its moisture content. If moisture is minimal in the soil, the exchanged energy is highly variable with a maximum difference of $17.4 \%$ in January and $14.6 \%$ in July. However, if moisture content is at its maximum, the recovered energy differences are similar: $2.9 \%$ in January and $1.9 \%$ in July. From these results, it can be concluded that when the soil type's moisture content is great, the soil type depends much less on energy performance. Furthermore, the addition of bentonite in the sand highlights the link between the storing of water and the subsequent improvement of the thermal performance of the EAHE.

\section{Conclusions}

A numerical finite element model has been proposed to simulate an EAHE system. The heterogeneity of soil's properties around the pipe and the thermal impact of the heat exchanger, in operation, are taken into account in the model. This model has been validated since a maximal difference of $3.6^{\circ} \mathrm{C}$ and a standard deviation of $0.5^{\circ} \mathrm{C}$ between model and data have been obtained. From the model, the thermal performance of the EAHE is studied, based on the soil for coating with six different configurations: three soil types for coating (sand, a mix composed of sand and bentonite, and in-situ earth) and two soil moistures (minimum and maximum measured in-situ). Differences in thermal performance reached $15.9 \%$ for the same soil with different moistures and $17.4 \%$ for a minimum humidity with different coating soils. However, if moisture content remains at its maximal value, soil type has an impact of only $2 \%$ on thermal performance. Based on these comparison results, it can be concluded that the choice of soil type for coating the EAHE can make a non-negligible influence on its thermal performance. The presence of a coating soil which has the capacity to store water, such as the mix of sand and bentonite, could be an appropriate solution to improve the thermal performance of the EAHE. A further study will be carried out by associating the EAHE system to typical buildings to evaluate the energy gain of this geothermal system in the global performance of the entire heating and cooling system within an actual building.

\section{References}

[1] M. Santamouris, D. Kolokosta, Passive cooling dissipation techniques for buildings and other structures: the state of the art, Energy Build. 57 (2013) 74-94, http://dx.doi.org/10.1016/j.enbuild.2012.11.002.

[2] M.H. Abbaspour-Fard, A. Gholani, M. Khojastehpour, Evaluation of an earth-to-air heat exchanger for north-east of Iran with semi-arid climate, Int. J. Green Energy 8 (2011) 499-510, http://dx.doi.org/10.1080/15435075.2011. 576289.

[3] Z. Li, W. Zhu, T. Bai, M. Zheng, Experimental study of a ground sink direct cooling system in cold areas, Energy Build. 41 (2009) 1233-1237, http://dx. doi.org/10.1016/j.enbuild.2009.07.020.

[4] C.O. Popiel, J. Wojtkowiak, B. Biernacka, Measurements of temperature distribution in ground, Exp. Therm. Fluid Sci. 25 (2001) 301-309, http://dx. doi.org/10.1016/S0894-1777(01)00078-4.

[5] F. Ascione, L. Bellia, F. Minichiello, Earth-to-air heat exchanger for Italian climates, Renew. Energ. 36 (2011) 2177-2188, http://dx.doi.org/10.1016/j. renene.2011.01.013.

[6] M. Barghouthi, S. Kooli, A. Farhat, H. Daghari, A. Belghith, Experimental investigation of thermal and moisture behavior of wet and dry soils with buried capillary heating system, Sol. Energy 79 (2005) 669-681, http://dx.doi. org/10.1016/j.solener.2005.06.011.

[7] S. Naylor, K.M. Ellett, A.R. Gustin, Spatiotemporal variability of ground thermal properties in glacial sediments and implications for horizontal ground heat exchanger, Renew. Energ. 81 (2015) 21-30, http://dx.doi.org/10. 1016/j.renene.2015.03.006.

[8] A. Trombe, B. Bourret, Contrat puits provençal -Expérimentation de l'INSA Laboratoire de thermique des matériaux et des bâtiments Toulouse, 1993.

[9] V.P. Kabashnikov, L.N. Danilevskii, I.P. Nekrasov, V.P. Viayaz, Analytical and numerical investigation of the characteristics of a soil heat exchanger for ventilation systems, Int. J. Heat Mass Transfer 45 (2002) 2407-2418, http:// dx.doi.org/10.1016/j.apenergy.2009.02.010.

[10] P. Tittelein, G. Achard, E. Wurtz, Modelling earth-to-air heat exchanger behaviour with the convolutive response factors method, Appl. Energ. 86 (2009) 1683-1691, http://dx.doi.org/10.1016/j.egyr.2014.11.004.

[11] R. Kumar, S. Ramesh, S.C. Kaushik, Performance evaluation and energy conservation potential of earth-air-tunnel system coupled with non-air-conditioned building, Build. Environ. 38 (2003) 807-813, http://dx. doi.org/10.1016/S0360-1323(03)00024-6.

[12] P. Hollmuller, Analytical characterization of amplitude-dampening and phase-shifting in air/soil heat-exchangers, Int. J. Heat Mass Transfer 46 (2003) 4303-4317, http://dx.doi.org/10.1016/S0017-9310(03)00199-6.

[13] S. Thiers, B. Peuportier, Thermal and environmental assessment of a passive building equipped with an earth-to-air heat exchanger in France, Sol. Energy 82 (2008) 820-831, http://dx.doi.org/10.1016/j.solener.2008.02.014.

[14] R. Kumar, S.C. Kaushik, S.N. Garg, Heating and cooling potential of an earth-to-air heat exchanger using artificial neutral network, Renew. Energ. 31 (2006) 1139-1155, http://dx.doi.org/10.1016/j.renene.2005.06.007.

[15] V. Bansal, R. Mishra, G.D. Agrawal, J. Mathur, Transient effect of soil thermal conductivity and duration of operation on performance of earth air tunnel heat exchanger, Appl. Energ. 103 (2013) 1-11, http://dx.doi.org/10.1016/j. apenergy.2012.10.014.

[16] A. Mathur, A. Srivastava, J. Mathur, S. Mathur, Transient effect of soil thermal diffusivity on performance of EATHE system, Energy Rep. 1 (2015) 17-21, http://dx.doi.org/10.1016/j.egyr.2014.11.004.

[17] H. Nowamooz, S. Nikoosokhan, J. Lin, C. Chazallon, Finite difference modelling of heat distribution in multilayer soils with time-spatial hydrothermal properties, Renew. Energy 76 (2014) 7-15, http://dx.doi.org/10.1016/j. renene.2014.11.008. 